to their agency. 4. It is probable that these germs, reaching internal organs, may be the means of a salutary elimination of morbid matter.

Holloway-road, $\mathbf{N}$.

\section{NOTE ON A CASE OF \\ AGUE APPARENTLY CURED AT THE BATH MINERAL WATER HOSPITAL.}

\section{BY JOHN KENT SPENDER, M.D. LOND.,} PHYSICIAN TO THE HOSPITAL.

IT hasalmost passed into a proverb that the chemical and therapeutic powers of our chief mineral waters are by no means fully known. Chance experiments sometimes bring to light a property which was previously unsuspected, just as salicin was long a familiar drug for trivial purposes before its anti-rheumatic virtues were discovered. Now I am going to relate, in the shortest way, a case which caused us no little surprise; and so little were we prepared for success that when the patient was admitted into our Mineral Water Hospital solely for the treatment of his one malady, intermittent fever, I laughed, and asked why he had travelled so far on such a seemingly bootless errand. He replied that he had been sent to Bath by his doctor, who believed that there was nothing else to be done; all else bad been tried, but no medicines had brought him permanent benefit. Without hope or faith (and faith has been described by a poet as "hope made wise") I ordered the man to bathe and drink the Bath waters secundum artem. with the sequel which shall be told as part of the history and in the patient's own words.

W. H-, aged forty, from Leighton Buzzard, admitted on Easter Monday, March 26tb, 1883. Two weeks before last Christmas he was "taken ill with influenza cold and rheumatism"; the legs, the upper part of the arms, and the loins were most severely affected, and he kept his bed for a month. Under the care of Mr. Wagstaff he "got better from the aching and cold, and then, on the second Monday in January, the 8th, ague set in." This began with gaping, shrugging of shoulders, and involuntary movements, which he compared to a child jumping in its sleep ; on the first day there was $\mathrm{n} n$ shivering nor not stage, and only a little sweating. Two days passed without a "tit," but on Thursday, the 11th, the phenomena were more marked, because there were both "hotness and sweating," Again, a day was missed, and on Saturday, the 13th, there were four attacks, the first at half-past six in the morning, the second at nine, the third at eleven, and the fourth at two o'clock. Of these the first was the worst, and during it he "brought up a great quantity of wind, and passed a lot of pale water," but the bowels were confined. From this time he had four attacks of the same sort on alternate days until he came to Bath, each "fit" being preceded by "twenty or thirty gapes within five minutes," and always followed by great prostration. The urine had a specific gravity of 1018, and contained no albumen. On Tuesday, March $28 \mathrm{th}$, the day after his admission into the hospital, W. H- had a "fit" of the same kind at half-past six and at nine o'clock. He bathed at ten o'clock; there was a slight attack at eleven, and a very slight one indeed at two o'clock on the same dav. From that moment he became, quoad ague, quite well. No medicine whatever was administered to him while he was in the hospital, except a few necessary aperient draugbte He was discharged "cured" early in May. Six weeks afterwards he wrote to me by special request. "I have not had any return of the ague since I have been home," he says. He adds, however, that he has a "bad eye," and occasional retching and purging, which " the doctor says is all from the effects of the ague"; but he was then so nearly recovered from all his troubles that he was soon going to work. The letter ends with a pathetic lament that be could have no more "mineral waters."

I see nothing which can vitiate the conclusion that this man's disease was removel by his " course of the Bath waters." He bathed on alternate days, and drank half a pint every day. Care was taken that he should not catch cold, and the diet was regulated; but not a grain of any specific drug was given. Finally, it may intelest his doctor, Mr. Wagstaff, to learn how much bis grateful pitient thught of his sagacity in sending him to Bath, and how poorly he thought of us for not knowing that ague could be cured by the Bath waters. I have looked through many old and modern records of "Bath physicians," but I cannot find any case at all like that of this working man from Leighton Buzzard.

Bath.

THE ACTION OF CONVALLARIA MAJALIS.

\section{BY GEORGE HERSCHELL, M.D. LOND,}

As this drug, which has lately been receiving a considerable share of attention, bids fair to come into general use in cardiac affections, and as it is believed to be devoid of injurious properties, the report of a case in which it had a decidedly untoward action may not be out of place. Nearly all the authorities who have written on convallaria are unanimous in according to it the action of digitalis and the absence of cumulative and toxic properties. To quote a few. Dr. Sée says that its effects are constant and constantly favourable, slowing the beating of the heart, often restoring its normal rhythm, augmenting the energy of the systole, and increasing the blood-pressure. Dr. D'Ary says that the physician will appreciate a remedy that will relieve signally and promptly without the dread of overdose and cumulative action. Dr. B. Stiller, ${ }^{1}$ on the other hand, gives a list of twenty-one cases treated by convallaria, in which absolutely negative results were obtained in seventeen, but makes no mention of an untoward effect in any. Dr. Taylor reports as his experience in twenty cases treated at the Roosevelt Hospital, New York, ${ }^{2}$ that in no case were any toxic symptoms observed. In view of this generally favourable impression as regards its properties, and the large doses recommended, the following case of functional derangement of the rbythm of the heart, in which five-minim doses pro. duced very alarming symptoms, may not be without interest.

The patient, Mr. C__ came under my observation for the first time on March 29 th of this year. He was apparently a healthy man of about middle age. His history was that, following some worry and overwork two years ago, his pulse had become irregular. This gave him absolutely no inconvenience beyond the fear on his own part that he was the victim of heart disease. He had been treated by several physicians with digitalis, ergot, and strychnia, and was still taking digitalis at the time I first saw him.

On making a physical examination I found that the cardiac dulness was normal; there were no murmurs over the heart region, and all the other organs of the body were perfectly healtby, but it was impossible to analyse either the pulse at the wrist or the heart-sounds as heard through the stethoscope. There was no dyspnoea, and the urine was quite normal both in quantity and quality.

The following sphygmographic tracing was now taken (see Chart 1). From this it will be seen that three or four

Chart 1.

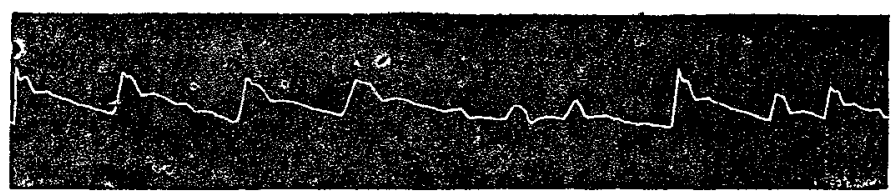

tolerably complete contractions of the heart are followed by about the same number of abortive ones, making a very interesting example of regularity in irregularity. Thinking that this was a suitahle case for convallaria, I ordered him to leave off the digitalis, so that I might be able to see what the pulse-trace would be without it. On July 17 th be came to me again, not having taken any digitalis since April, and I to ok the followiog (see Chart 2). He was now

Chart 2.

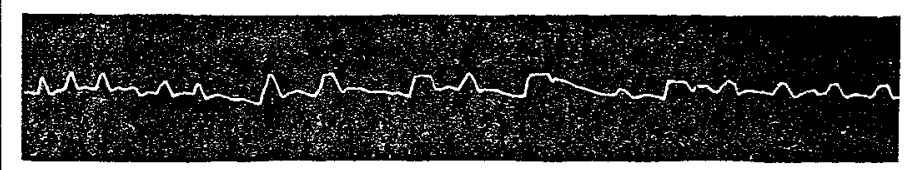

order d five minims of tincture of convallaria three times a day, but was obluged to discontiuue it after a few doses on account of the following remarkable effects. Almost directly

1 Wiener Medizinische Wochengchrift. = Med. Record, Jan. 27, 1883. 
after each dose the pulse becaine nearly imperceptible at the wrist, and he suffered fromi a sense of oppression over the sternum, nausea, cold feet, vertigo, flatulence, and a feeling of utter prostration. These symptoms lasted two hours, and then subsided, only to reappear directly the next dose was taken. The following was taken shortly after a dose (see Chart 3). The convallaria being now discontinued,

Chart 3.

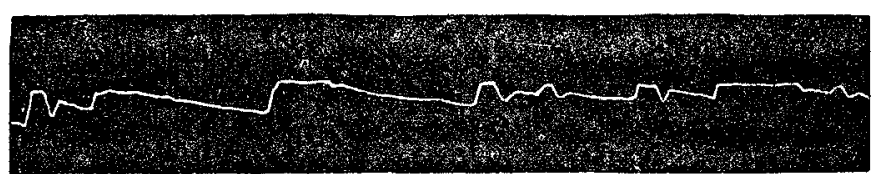

the patient was ordered digitalis again, and a glance at the accompanying trace (Chart 4) will show how great an improvement has already taken plase.

Chart 4.

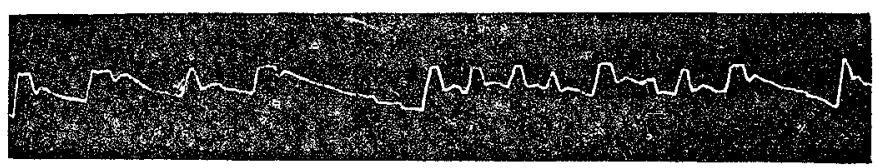

All these tracings were taken with a pressure of two ounces upon the right radial artery, with Dudgeon's sphyg. mograph. Taking Chart 2 to be the trace of the heart un influenced by medication, we observe that while in Chart 3, the one taken while under the influence of convallaria, the interval between the cardiac contractions is notably increased without any compensatory increase in their strength, in Chart 1 and Chart 4 , while under treatment by digitalis, there is marked increase not only in the interval between the beats, but also in the height of the upstroke. In Chart 4 especially, great improvement in the shape of the curve is evident, the aortic notch and secondary rise being very well marked in most of the beats.

From the study of this interesting case we may gather two things. First, that the actions of convallaria and digitalis are not quite so identical as seems to have been assumed and, secondly, that we must be very careful, in giving it to a patient who is taking it for the first time, to begin at a dose much below that quoted as the minimum in most of the writings upon the subject.

Moorgate-street, E.C.

\section{9 attirtor \\ OF}

\section{HOSPITAL PRACTICE, BRITISH AND FOREIGN.}

Nulla autem est alia pro certo noscendi via, nisi quamplurimas et morborum et dissectionum historias, tum aliorum tum proprias collectas habere, e inter se comparare.-MongagNi De Sed. et Caus. Morb., lib. iv. Procemium.

\section{CHARING-CROSS HOSPITAL.}

TRAUMATIC ANEURISM OF THE PALM ; OPERATION OF LAYING OPEN THE SAC ; RECOVERY.

(Under the care of Mr. BELLAMY.)

THE treatment of every case of wound of the vessels in the palm is a problem to be solved, and is important as a surgical record.

The introduction of Esmarch's bandage has revolutionised the older treatments of wounds of the palm. Its application admits of a studied and careful dissection in search of the bleeding point or points, which with ordinary anatomical knowledge and manipulative skill should be found. Tentative ligature of the radial, ulnar, interosseous, or even median, and the last severe resort of ligature of the brachial, are assuredly in the highest degree unwarrantable at an early stage. Added to which, if the operation be conducted on strict antiseptic principles, there is no dread of mischief aiter searching about in the palm.

A. B- a fine young man, aged twenty-three, came into the hospital, having been injured in the palm by some broken glass, the result of a cab accident, on Sept, $26 \mathrm{th}$. There was free hæmorrhage from the wound, spirting from a gash in the usual course of the ulnar portion of the superficial arch. Pressure, however, on both ulnar and radial vessels at the wrist did little to control it ; consequently it was supposed that there was an enlarged median, which supplied the blood. Mr. Bellamy passed a stout hare lip pin beneath the supposed site of the bleeding point on either side of the cut in the hand, and with the effect of completely controlling the bleeding for the time being. The needles were removed on the fourth day. All went well for fourteen days, when possibly after using the hand too soon, a traumatic aneurism developed in the palm, and the patient returned to the hospital. He was told to remain in, but preferred to go home for the night and return early for treatment next day. On his way by train the tumour gave way, with profuse hæmorrhage; this he stopped by pressing his finger on the bleeding point until he came to the hospital. He was taken. to the operating theatre, and, an anæsthetic being given, an Esmarch's bandage was applied, strict antiseptic precautions being adopted. An incision was made down upon the sac, the clot was turned out, and the source of bleeding sought for, which was enlarged by a transverse one across the palm to get more room. Fortunately it was speedily found-a longitudinal slit in the course of the trunk of a somewhat irregular distribution of the ulnar artery, just in front of the furrow, between the commencement of the thenar and hypothenar eminences. A catgut ligature was applied, with an aneurism needle above and below the wound in the vessel, and the vessel itself divided between the points of ligature. The Esmarch bandage was then removed, an assistant having command of the brachial. No bleeding occurred from the ulnar, but presently a somewhat profuse hæmorrhage came on from the surrounding cut tissues and deep structure. This was undoubtedly from enlarged anastomotic vessels. The bleeding points were tied or torsioned, and when all oozing had ceased the wound was plugged with a small carbolised sponge, and Listerian compresses and bandages applied. A dorsal splint was ad justed, and the limb slung on an extension boom over the bed's head. The dressings were examined antiseptically on Monday, the 15th, and all bleeding had ceased, the wound looking healthy and well.

\section{STAMFORD, RUTLAND, AND GENERAT INFIRMARY.}

INCISED WOUND FOLLOWED BY TETANUS ; RECOVERY.

(Under the care of Mr. GREENwOOD.)

W. D-, male, aged twenty.one, a farm labourer, was on Sept. 2nd, 1882, sharpening his scythe, when he let it fall across his arm.

On admission, about two hours afterwards, there was an incised wound extending along the front and outer side of the left elbow-joint. On the outer side it extended down to the capsule of the joint, but the inner side of the wound was only skin deep. The wound was very dirty. It was well eleansed with carbolic lotion ( 1 in 40); several small arterial branches twisted, and two fine catgut ligatures were applied to the median basilic vein, which was punctured and bleeding freely. A small-sized drainage-tube was put in, and the edges of the wound were brought together with silver wire sutures. The arm was put on an angular splint, and boracic dressings were applied.-Sept. 10th : For the first four days there was some oedema of the part; discharge was slight and not offensive ; drainage-tube only an inch long now; all but three sutures removed.12th: Wound looks well, nearly sound; tube removed; patient got up.-13th : Thinks he has got cold; throat sore. -14th: Feels stifia about the lower jaw. Ordered thirty grains of bromide of potassiumevery four hours. Tetanussuspected. 15 th, 10 A.M. : Can only open his mouth about a quarter of an inch; muscles of the neck rigid. Ordered thirty grains of bromide with twenty grains of chloral every four hours. 5 P.M. : Worse ; to continue medicine, and to have an hypodermic injection of one-sixtieth of a grain of sulphate of atropia every sixth hour in addition. 10 P. M. : All of his muscles are more or less rigid, and spasms frequent; slight risus sardonicus ; no opisthotonos ; complains much of pain in his limbs and chest. Sutures removed and wound poulticed. 16th and 17th : Remained about the same, taking a fair amount of beef-tea and milk by the mouth, and four fluid ounces of brandy in the twenty-four hours -18th : Spasms and pain increasing. Ordered twenty grains of bromide with fifteen minims of Battley s solution of opium every 